\title{
KEANEKARAGAMAN MIKROALGA DI SUNGAI KATI KOTA LUBUKLINGGAU
}

\author{
HARMOKO, SEPRIYANINGSIH
}

Program Studi Pendidikan Biologi STKIP PGRI Lubuklinggau, Jalan Mayor Toha Kota Lubuklinggau 31628

\section{A B S T R A C T}

We conducted an initial survey of the microalgal diversity of Kati River located in the City of Lubuklinggau, South Sumatra Province, on March to May 2017. This study aimed to determine the microalgal diversity of Kati River as a baseline data. This study found 47 microalgal species belonging to 42 genera and 27 orders. We found the member of Chlorophyceae and Bacillariophyceae were the most abundant microalgae. We also compared the diversity of Kati River to two other rivers in Lubuklinggai, Mesat River, and Kalingi River. The microalgal diversity of Kati River is higher than Mesat River but lower if compared to Kalingi River. The physicochemical factors of Kati River waters were also measured, the average water temperature was $27^{\circ} \mathrm{C}$, average $\mathrm{pH}$ was 6.7 , and average water transparency was $57 \mathrm{~cm}$. This study found that those environmental factors influenced microalgal diversity in Lubuklinggau rivers, Kati River, as well as Mesat River and Kalingi Rivers, have indicated the same results.

KEY WORDS: biodiversity, mikroalga, Sungai Kati, Lubuklinggau

\section{PENDAHULUAN}

Kota Lubuklinggau adalah salah satu kota di Sumatera Selatan yang memiliki banyak sungai-sungai kecil, di antaranya adalah Sungai Belabu, Sungai Bunginjawi, Sungai Megang, Sungai Kelingi, Sungai Mesat, Sungai Temam, Sungai Tiga, Sungai Semi, dan Sungai Kati yang semuanya bermuara di Sungai Beliti. Sungai Kati yang juga disebut Sungai Jukung karena melintasi Desa Kati dan Desa Jukung terletak di Kecamatan Lubuklinggau Selatan I. Sebagaimana semua sungai lain di kota ini, Sungai Kati berfungsi sebagai sumber air utama irigasi lahan persawahan dan kolam ikan air deras, serta kebutuhan hidup sehari-hari masyarakat sekitar sungai (Saleh, 2014; Biro Pusat Statisik Kota Lubuklinggau, 2017a, 2017b). Namun demikian kualitas air sungai di Kota Lubuklinggau mulai terancam oleh aktivitas manusia seperti penambangan batu koral di Sungai Kelingi (Mongabay Indonesia, 2014) dan pembuangan sampah serta limbah rumah tangga yang terjadi hampir ke semua sungai di Kota Lubuklinggau (Pemerintah Kota Lubuklinggau, 2017). Sungai Kati merupakan salah satu sungai yang masih terjaga kualitas airnya, sehingga kajian mengenai diversitas mikroalga di sungai ini perlu dilakukan sebagai data dasar terkait dengan kualitas airnya.

Metode biologi terstandarisasi untuk menguji kualitas air telah dikenal secara luas dan dapat dianalisis serta dipahami dengan mudah (Plafkin et al., 1989). Metode biologi dapat digunakan untuk mengetahui adanya polusi dan perubahan lingkungan, tingkat toksisitas polutan dan dampaknya terhadap lingkungan, akumulasi polutan pada biota dan pengaruhnya terhadap rantai makanan, serta pengaruh polutan, penggunaan air, dan tanah terhadap ekosistem (Norris \& Morris, 1995).

Monitoring kualitas air sungai dapat dilakukan dengan menggunakan parameter fisik atau kimia, tetapi pemantauan dengan biota air lebih banyak dilakukan. Kondisi biota air lebih jelas dalam merepresentasikan perubahan kualitas air sungai, termasuk adanya pencemaran perairan, karena biota air tersebut berada di dalam lingkungan air sungai dalam kurun waktu yang lama, sedangkan nilai kondisi fisik dan kimia air cenderung menggambarkan keadaan air sungai pada waktu pengukuran saja. Di samping itu, pengamatan biota air lebih murah dalam pembiayaan, cepat, mudah diinterpretasikan dan cukup sahih untuk menunjukkan kualitas lingkungan perairan (Winarno et al., 2000).

Mikroalga secara umum diketahui sebagai biota air yang dapat dijadikan sebagai bioindikator untuk melihat kualitas suatu perairan (Andriansyah et al., 2014; Giasi et al., 2015; Purba et al., 2015). Mikroalga sebagai salah satu parameter ekologi dapat memberikan gambaran keadaan perairan dan termasuk salah satu komponen biotik penting dalam metabolisme badan air, karena merupakan mata rantai primer di dalam rantai makanan ekosistem perairan (Samudra et al., 2012), penting bagi kehidupan ikan dan organisme air lain, sehingga keberadaannya sangat menentukan kondisi ekosistem (Odum, 1983).

Ukuran diversitas mikroalga suatu perairan dinyatakan sebagai jumlah species mikroalga yang terdapat di perairan tersebut. Semakin besar jumlah species maka semakin tinggi pula nilai diversitasnya. Hubungan antara jumlah species dengan jumlah individu dapat dinyatakan dalam bentuk indeks diversitas (Astirin et al., 2002).

Penelitian ini bertujuan untuk mengetahui diversitas mirkroalga Sungai Kati yang hasilnya dapat digunakan sebagai data dasar kualitas air, untuk perbandingan dengan sungai lain, maupun untuk evaluasi perubahan kualitas air sungai tersebut di masa yang akan datang. 


\section{MET O DE}

Penelitian ini adalah penelitian survei. Sampel mikroalga diambil dari Sungai Kati, Kecamatan Lubuklinggau Selatan I, Kota Lubuklinggau. Sampel diambil dari 3 stasiun berdasarkan kriteria topologi ekosistem yang berbeda (Gambar 1 dan 2), masing-masing dengan 3 pengulangan waktu. Pengambilan sampel dilakukan pada bulan MaretMei 2017. Sampel mikroalga kemudian diamati dan diidentifikasi di laboratorium Biologi STKIP-PGRI.

Alat yang digunakan dalam penelitian ini adalah plankton net ukuran mesh 20, mikroskop binokuler, $\mathrm{pH}$ meter, Secchi-disk, dan termometer. Bahan yang digunakan dalam penelitian ini adalah air sampel dan etanol $85 \%$ sebagai pengawet sampel mikroalga.

Identifikasi jenis mikroalga secara morfologi mengacu pada Belcher \& Swale (1976), Vuuren, et al. (2006), Botes (2001), Wehr \& Sheath (2003), dan Bellinger \& David (2010).

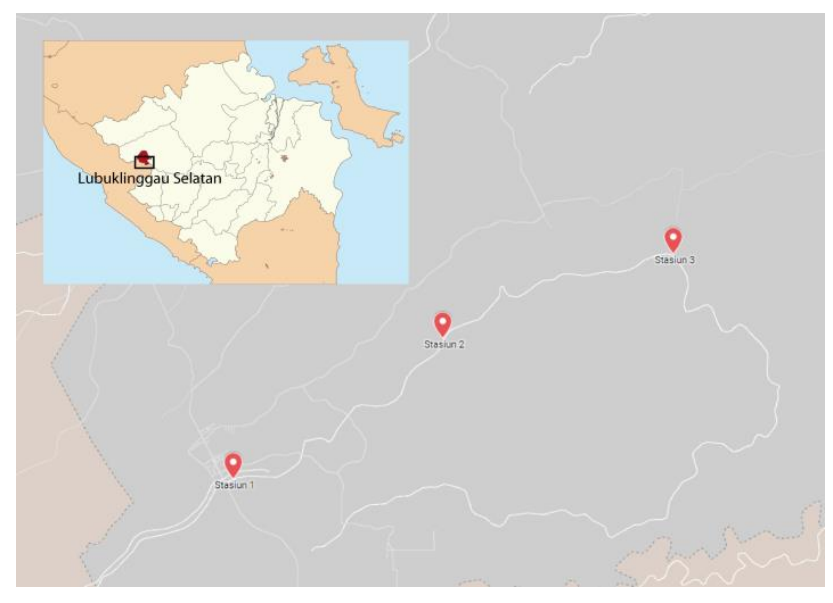

Gambar 1. Peta lokasi pengambilan sampel di Sungai Kati, Kecamatan Lubuklinggau Selatan I, Kota Lubuklinggau.

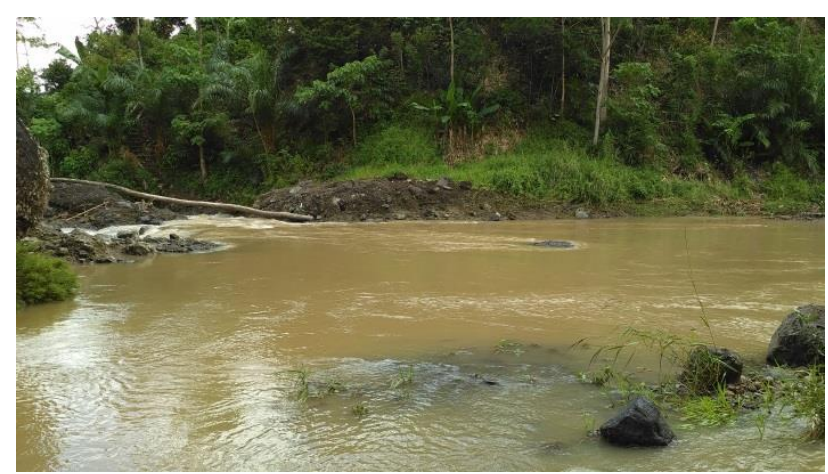

Gambar 2. Foto lokasi pengambilan sampel di Sungai Kati, Kecamatan Lubuklinggau Selatan I, Kota Lubuklinggau pada Stasiun 1.

\section{HASIL DAN PEMBAHASAN}

Mikroalga yang ditemukan di Sungai Kati Kecamatan Lubuklinggau Selatan I Kota Lubuklinggau adalah 47 species yang terbagi dalam 42 genera, 27 ordo, dan 5 divisio. Jumlah jenis terbanyak ditemukan di stasiun 1 yaitu 36 species, sedangkan pada stasiun 2 ditemukan 30 species, dan di stasiun 3 sebanyak 22 species (Tabel 1). Faktor lingkungan Sungai Kati pada saat pengambilan sampel tercatat untuk rata-rata suhu adalah $27^{\circ} \mathrm{C}$, nilai rerata $\mathrm{pH} 6,7$, dan rerata kecerahan air $57 \mathrm{~cm}$ (Tabel 2).
Penelitian ini merupakan bagian dari penelitian payung yang berusaha mengetahui keanekaragaman mikroalga di Kota Lubuklinggau. Pada tahun pertama (2016) ruang lingkup kajiannya adalah air terjun, yakni Air Terjun Temam (Sintya et al., 2016) dan Air Terjun Watervang (Harmoko et al., 2017). Tahun kedua (2017) ruang lingkupnya adalah perairan sungai di Kota Lubuklinggau, yaitu Sungai Kelingi (Susanto et al., 2017), Sungai Mesat (Aziz, 2017), dan penelitian ini pada Sungai Kati.

Keanekaragaman mikroalga di Sungai Kati berkisar antara 22-36 jenis dengan total jenis 47 dari 3 stasiun pengambilan sampel, lebih tinggi bila dibandingkan dengan Sungai Mesat yang berkisar antara 15-19 jenis dengan total jenis 32 (Aziz, 2017), namun lebih rendah bila dibandingkan dengan Sungai Kelingi yang berkisar antara 37-41 jenis dengan total jenis 63 (Susanto et al., 2017). Chlorophyta merupakan kelompok mikroalga dengan diversitas jenis yang paling banyak ditemukan di Sungai Kati, serta Bacillariophyta pada urutan kedua.

Chlorophyta yang ditemukan di Sungai Kati tersusun atas 20 species dari 20 genera. Genera dari Chlorophyta yang ditemukan tersebut yaitu Oocystis, Micractinium, Scenedesmus, Pediastrum, Chlorococcum, Tetraedron, Cloesterium, Cosmarium, Gonatozygon, Ulothrix, Drafanaldia, Chlorella, Spirogyra, Mougeotia, Zygnema, Eudorina, Chlamydomonas, Oedogonium, Microspora dan Ankistrodesmus. Jenis Chlorophyta di Sungai Kati ditemukan lebih rendah dibanding Sungai Kelingi yaitu 27 jenis (Susanto et al., 2017), dan ditemukan dalam jumlah yang sama di Sungai Mesat yaitu 20 jenis (Aziz, 2017). Pada ketiga sungai di Kota Lubuklinggau tersebut Chlorophyta merupakan kelompok penyusun mikroalga yang paling banyak ditemukan. Hal yang sama dengan beberapa penelitian sebelumnya yang menemukan Chlorophyta merupakan mikroalga yang banyak ditemukan di perairan Sungai Musi (Zuklifli et al., 2012), Sungai Pepe (Sundari, 2016), termasuk Sungai Kelingi (Susanto et al., 2017), dan Sungai Mesat (Aziz, 2017). Prasetyo \& Elizabeth (2013) menyatakan tingginya jumlah species Chlorophyta pada suatu lingkungan perairan dapat mengindikasikan bahwa kemungkinan besar telah mengalami pencemaran kategori sedang, dan oleh karena itu Chlorophyta dapat menjadi bioindikator dari lingkungan ekosistem air yang sedang mengalami stres.

Bacillariophyta yang ditemukan di Sungai Kati terdiri atas 19 species dari 15 genera. Genera dari Bacillariophyta yang merupakan mikroalga terbanyak kedua setelah Chlorophyta yang ditemukan yaitu Tabellaria, Melosira, Navicula, Pinnularia, Asterionella, Eunotia, Surirella, Nitschia, Pleurosigma, Synedra, Fragillaria, Gomphonema, Cylotella, Aulacaseira dan Guinardia. Bacillariophyta atau diatom umum ditemukan sebagai kelompok produsen primer dominan maupun subdominan kecuali pada sungai berlumpur (Zuklifli et al., 2012; Sundari, 2016; Winahyu et al., 2013). 
Tabel. 1. Jenis Mikroalga di Sungai Kati, Kecamatan Lubuklinggau Timur 1 Kota Lubuklinggau

\begin{tabular}{|c|c|c|c|c|c|}
\hline \multirow{2}{*}{ No Divisio } & \multirow{2}{*}{ Ordo } & \multirow{2}{*}{ Species } & \multicolumn{3}{|c|}{ Stasiun } \\
\hline & & & 1 & 2 & 3 \\
\hline \multirow[t]{20}{*}{ 1. Chlorophyta } & Chlorococcales & Oocystis sp & & $\bullet$ & \\
\hline & & Micractinium sp & - & $\bullet$ & - \\
\hline & & Scenedesmus sp & - & & \\
\hline & & Pediastrum sp & & $\bullet$ & - \\
\hline & & Chlorococcum sp & • & & \\
\hline & & Tetraedron sp & - & $\bullet$ & - \\
\hline & Desmidiales & Cloesterium sp & - & • & - \\
\hline & & Cosmarium sp & - & $\bullet$ & - \\
\hline & & Gonatozygon sp & & $\bullet$ & \\
\hline & Ulotricales & Ulothrix sp sp & • & $\bullet$ & \\
\hline & Chaetophorales & Drafanaldia sp & - & $\bullet$ & \\
\hline & Chlorellales & Chlorella sp & • & $\bullet$ & \\
\hline & Zygnematales & Spirogyra sp & - & $\bullet$ & - \\
\hline & & Mougeotia sp & $\bullet$ & $\bullet$ & \\
\hline & & Zygnema sp & & $\bullet$ & • \\
\hline & Chlamydomonadales & Eudorina sp & - & & - \\
\hline & Volvocales & Chlamydomonas sp & - & $\bullet$ & - \\
\hline & Oedogoniales & Oedogonium sp & - & & \\
\hline & Sphaeropleales & Microspora sp & - & $\bullet$ & • \\
\hline & & Ankistrodesmus sp & & & • \\
\hline \multirow[t]{19}{*}{ 2. Bacillariophyta } & Tabellarialles & Tabellaria $\mathrm{sp}$ & $\bullet$ & $\bullet$ & - \\
\hline & & Tabellaria flocculosa & - & & \\
\hline & Biddulphiales & Melosira sp & & $\bullet$ & \\
\hline & Naviculales & Navicula sp & - & $\bullet$ & - \\
\hline & & Pinnularia sp & & $\bullet$ & \\
\hline & Eunotiales & Asterionella $\mathrm{sp}$ & $\bullet$ & $\bullet$ & \\
\hline & & Eunotia sp & & & • \\
\hline & Surirellales & Surirella sp & - & $\bullet$ & • \\
\hline & & Surirella elegans & $\bullet$ & $\bullet$ & \\
\hline & & Surirella robusta & $\bullet$ & $\bullet$ & • \\
\hline & Bacillariales & Nitschia sp & $\bullet$ & & • \\
\hline & & Pleurosigma $\mathrm{sp}$ & & $\bullet$ & \\
\hline & Fragillariales & Synedra sp & $\bullet$ & & • \\
\hline & & Fragillaria sp & $\bullet$ & $\bullet$ & • \\
\hline & Pennales & Gomphonema sp & $\bullet$ & $\bullet$ & \\
\hline & Thalassiosirales & Cylotella sp & $\bullet$ & & • \\
\hline & & Cylotella quilensis & $\bullet$ & & \\
\hline & Centrales & Aulacaseira sp & $\bullet$ & & \\
\hline & Rhizosoleniales & Guinardia sp & $\bullet$ & $\bullet$ & \\
\hline \multirow[t]{6}{*}{ 3. Cyanobacteria } & Chroococcales & Actinastrum sp & $\bullet$ & $\bullet$ & • \\
\hline & Oscillatoriales & Oscillatoria sp & $\bullet$ & $\bullet$ & \\
\hline & & Oscillatoria limosa & & • & \\
\hline & Nostocales & Anabaena sp & • & & \\
\hline & & Calothrix sp & $\bullet$ & & \\
\hline & Synechococcales & Agmenellum sp & $\bullet$ & & \\
\hline & Tribonematales & Tribonema sp & & & - \\
\hline \multirow{2}{*}{ 5. Euglenophyta } & Euglenales & Euglena sp & • & & \\
\hline & & & 36 & 30 & 22 \\
\hline
\end{tabular}

Bacillariophyta memiliki kemampuan beradaptasi terhadap arus yang kuat maupun lambat karena memiliki alat penempel pada substrat berupa tangkai bergelatin (Andriansyah et al., 2014). Bacillariophyta juga merupakan bioindikator yang telah banyak digunakan untuk mengetahui tingkat pencemaran suatu perairan (Winahyu et al., 2013).

Cyanobacteria yang ditemukan di Sungai Kati terdiri atas 6 species dari 5 genera. Genera dari Cyanobacteria yang ditemukan meliputi Actinastrum, Oscillatoria, Anabaena, Calothrix, dan Agmenellum. Cyanobacteria biasanya terdiri dari beberapa mikroalga hijau-biru dan bersifat unisesuler, berfilamen atau berkoloni, tidak memiliki membran internal, tidak memiliki organel/nukleus, dan warna alga ini hijau-biru, hijau-hijau, ungu, cokelat, merahjingga tergantung pada konsentrasi pigmen klorofil, fikosianin, dan fikoeritin (Pratiwi, 2008). Cyanobacteria membutuhkan suhu yang relatif lebih tinggi untuk berkembang dengan baik. Pada penelitian ini suhu rata-rata perairan Sungai Kati pada saat penelitian adalah $27^{\circ} \mathrm{C}$, kisaran suhu tersebut bukanlah suhu ideal bagi pertumbuhan Cyanobacteria (Andriansyah et al., 2014).

Kelompok mikroalga yang paling sedikit ditemukan di Sungai Kati yaitu Xanthophyta dan 
Euglenophyta. Pada saat pengambilan sampel hanya ditemukan 1 genus dari Xanthophyta yaitu Tribonema, dan 1 genus dari Euglenophyta yaitu Euglena. Xanthophyta merupakan alga hijau-kuning, mempunyai dua flagel yang tidak sama panjang, unisesuler, membentuk koloni, berfilamen, atau berbentuk tabung dan produk metabolit cadangannya adalah minyak (Pelczar, 2010). Xanthophyta biasa ditemukan sebagai fitoplankton danau dan waduk terutama yang kaya akan bahan organik dan humat (Bellinger \& Sigee, 2010). Euglenophyta merupakan mikroalga unisesuler, bergerak aktif atau berenang bebas menggunakan satu atau dua flagel, berbentuk memanjang tapi dapat ditemukan berbentuk spindel atau bengkok, periplast fleksibel, biasanya melimpah pada kolam dan perairan dangkal, reproduksi terjadi secara pembelahan biner, memiliki sista dorman dan memiliki bintik mata yang jelas (Pratiwi, 2008; Pelczar, 2010; Bellinger \& Sigee, 2010). Kondisi sungai yang deras menjadi alasan kuat kenapa Euglenophyta sangat jarang ditemukan di Sungai Kati.

Faktor lingkungan mikroalga berupa suhu di Sungai Kati tercatat dengan rerata $27^{\circ} \mathrm{C}$. Suhu dengan nilai tersebut merupakan suhu yang ideal untuk pertumbuhan mikroalga. Suhu lingkungan di suatu perairan sangat mempengaruhi pertumbuhan mikroalga dan batas suhu optimum pertumbuhan mikroalga adalah sekitar $20-30^{\circ} \mathrm{C}$ (Pratiwi 2008; Hajoeningtijas, 2012).

Nilai pH rata-rata Sungai Kati yang diperoleh saat penelitian yaitu 6,7. Nilai $\mathrm{pH}$ yang menunjukan aktivitas ion hidrogen dalam suatu perairan mencerminkan keseimbangan asam-basa perairan tersebut (Winahyu et al., 2013). Penyerapan $\mathrm{CO}_{2}$ bebas dan bikarbonat oleh mikroalga menyebabkan penurunan konsentrasi $\mathrm{CO}_{2}$ terlarut dalam air dan mengakibatkan peningkatan nilai $\mathrm{pH}$ (Prihantini et al., 2008). Derajat pH suatu lingkungan perairan sering dipakai untuk menentukan baik buruknya suatu lingkungan hidup, meskipun kondisi suatu perairan juga dipengaruhi oleh beberapa faktor lain (Erdina et al., 2010). Nilai pH optimum untuk pertumbuhan mikroalga adalah berkisar antara 4-11 (Pelczar, 2010; Pratiwi, 2008).

Tabel 2. Hasil pengukuran faktor lingkungan Sungai Kati

\begin{tabular}{clr}
\hline No. & Parameter & Rerata \\
\hline 1. & Suhu & $27^{\circ} \mathrm{C}$ \\
2. & pH & 6,7 \\
3. & Kecerahan & $57 \mathrm{~cm}$ \\
\hline
\end{tabular}

Faktor lingkungan lain berupa kecerahan perairan, diukur dengan menggunakan secchi disk. Kecerahan rata-rata Sungai Kati yaitu sebesar $57 \mathrm{~cm}$ atau 0,57 m. Kecerahan ini termasuk rendah karena saat pengambilan data kondisi air Sungai Kati keruh akibat hujan. Kecerahan atau penetrasi cahaya merupakan salah satu faktor penting bagi pertumbuhan mikroalga karena berpengaruh secara langsung untuk proses fotosintesis. Kondisi perairan dapat dibedakan menjadi tiga berdasarkan tingkat kecerahannya, yakni perairan keruh apabila nilai kecerahannya $0,25-1,00$ $\mathrm{m}$, perairan sedikit keruh apabila memiliki nilai kecerahan 1,00-5,00 m, dan perairan jernih memiliki nilai kecerahan di atas 5,00 m (Prasetyo \& Elizabeth, 2013).

Keterkaitan ketiga faktor lingkungan tersebut dengan keanekaragaman mikroalga Sungai Kati dapat dilihat bila dibandingkan dengan Sungai Mesat dan Sungai Kalingi, dimana nilai ketiga faktor lingkungan berbanding lurus dengan keanekaragaman mikroalga di ketiga sungai tersebut. Tercatat keanekaragaman mikroalga di Sungai Mesat, Sungai Kati, dan Sungai Kalingi berturut turut dengan nilai kisaran dan nilai keragaman total adalah sebagai berikut 15-19 (32) jenis (Aziz, 2017), 22-36 (47) jenis, dan 37-41 (63) jenis (Susanto et al., 2017). Sedangkan faktor lingkungan terukur untuk suhu, $\mathrm{pH}$, dan kecerahan pada ketiga sungai tersebut secara berurutan adalah sebagai berikut, Sungai Mesat $(25,3 ; 7,2 ; 18,0)$ (Aziz, 2017), Sungai Kati $(27,0 ; 6,7 ; 57,0)$, dan Sungai Kalingi $(25,4 ; 7,31 ; 44,0)$ (Susanto et al., 2017).

\section{KESIMPULAN DAN SARAN}

Keanekaragaman mikroalga yang ditemukan di Sungai Kati Kecamatan Lubuklinggau Selatan I Kota Lubuklinggau adalah 47 Species yang terbagi dalam 42 genera, 27 ordo, dan 5 Divisio. Berdasarkan perbandingan dengan Sungai Mesat dan Sungai Kalingi di Kota Lubuklinggau, Sungai Kati mempunyai nilai keanekaragaman mikroalga di antara kedua sungai tersebut, lebih tinggi dari Sungai Mesat namun lebih rendah dari Sungai Kalingi.

Selanjutnya perlu dilakukan monitoring atau penelitian berkala untuk melihat dinamika keanekaragaman mikroalga di Sungai Kati sebagai bioindikator untuk melihat perubahan kualitas air sungai tersebut.

\section{AF T AR REFERENS I}

Andriansyah, Setyawati TR, Lovadi I. 2014. Kualitas Perairan Kanal Sungai Jawi dan Sungai Raya Dalam Kota Pontianak Ditinjau dari Struktur Komunitas Mikroalga Perifitik. J.Protobiont. 3(1):61-70.

Astirin OP, Setyawan AD, Harini M. 2002. Keragaman Plankton sebagai Indikator Kualitas Sungai di Kota Surakarta. Biodiversitas. 3(2):236-241.

Aziz L, Trihayanti M, Harmoko. 2017. Inventarisasi Mikroalga di Sungai Mesat Kecamatan Lubuklinggau Timur II Kota Lubuklinggau. [Internet]. Available from: http:// repository. mipastkipllg.com/.

Belcher H, Swale E. 1978. A Beginner's Guide To Freshwater Algae. London: Institute of Terrestrial Ecology.

Bellinger EG, Sigee DC. 2010. Freshwater Algae. England: WileyBlackwell.

Biro Pusat Statisik Kota Lubuklinggau. 2017a. Kota Lubuklinggau Dalam Angka. BPS Kota Lubuklinggau. pp.342.

Biro Pusat Statisik Kota Lubuklinggau. 2017b. Kecamatan Lubuklinggau Selatan I Dalam Angka. BPS Kota Lubuklinggau. pp.84.

Botes L. 2001. Phytoplankton Identification Catalogue. South Africa: Glaballast Monograph.

Erdina L, Aulia A, Hardiansyah. 2010. Keanekaragaman dan Kemelimpahan Alga Mikrokopis Pada Daerah Persawahan Di Desa Sungai Lumbah Kecamatan Alalak Kabupaten Barito Kuala. Barito Kuala. J.Wahana-Bio. 1(3):72-91. 
Giasi C, Ramli U, Abubakar SK. 2015. Identifikasi Mikroalga Epilitik sebagai Biomonitoring Lingkungan Perairan Sungai Bone. Gorontalo: Universitas Gorontalo.

Hajoeningtijas OD. 2012. Mikrobiologi Pertanian. Yogyakarta: Graha Ilmu.

Harmoko H, Lokaria E, Misra S. 2017 Eksplorasi mikroalga di air terjun watervang kota lubuklinggau. Bioedukasi (Jurnal Pendidikan Biologi). 8(1):75-82.

Mongabay Indonesia. 2014. Keindahan- sungai- kelingilubuklinggau- terancam- memudar. Kenapa?. [Internet]. Available from: http:// www.mongabay.co.id/ 2014/ 08/ 17/.

Norris RH, Morris KR. 1995. The need for biological assessment of water quality: Australian perspective. Australian Journal of Ecology. 20:1-6.

Odum FP. 1983. Principles of Ecology. Philadelphia: W.B. Saunders

Pelczar MZ. 2010. Dasar-dasar Mikrobiologi. Jakarta: Universitas Indonesia.

Pemerintah Kota Lubuklinggau. 2013. Lampiran Perda Kota Lubuklinggau Nomor 1 Tahun 2013 Tentang Rencana Pembangunan Jangka Menengah Daerah Kota Lubuklinggau Tahun 2013-2017. [Internet]. Available from: http://bappeda.lubuklinggaukota.go.id/.

Plafkin JL, Barbour MT, Porter KD, Gross SK, Hughes RM. 1989. Rapid bioassessment protocols for use in streams and rivers: benthic macroinvertebrates and fish. EPA.

Prasetyo B, Elizabeth NK. 2013. Lingkungan Fisik dan Kekayaan Mikroalga di Danau Universitas Terbuka, Tangerang Selatan. J. Matematika, Sains, dan Teknologi. 14(2):120-126.

Pratiwi ST. 2008. Mikrobiologi Farmasi.Yogyakarta: Erlangga.

Prihantini NB, Wisnu W, Dian H, Arya W, Yuni A, Ronny R. 2008. Biodiversitas Cyanobacteria dari Beberapa Situ/Danau di Kawasan Jakarta-Depok-Bogor, Indonesia. J. Makara, Sains. 12 (1): 44-54.

Purba IYS, Izmiarti, Solfiyeni. 2015. Komunitas Algae Epilitik Sebagai Indikator Biologis di Sungai Batang Ombilin, Sumatera Barat. J. Biologi Universitas Andalas 4(2): 138-144.
Saleh E. 2014. Studi Konflik Air Irigasi dan Alternatif Penyelesaiannya di Daerah Irigasi Kelingi Sumatera Selatan. Jurnal Keteknikan Pertanian. 24(1):39-43.

Samudra SR, Tri RS, Munifatul I. 2012. Komposisi, Kemelimpahan dan Keanekaragaman Fitoplankton Danau Rawa Pening Kabupaten Semarang. J. Bioma, Vol. 15(1):6-13.

Sintya AD, Lokaria E, Si MP. 2016. Identifikasi Alga Mikroskopis di Air Terjun Temam Kota Lubuklinggau. [Internet]. Available from: http:// repository.mipastkipllg.com/.

Sundari PPK. 2016. Identifikasi Fitoplankton di Perairan Sungai Pepe sebagai Salah Satu Anak Sungai Bengawan Solo di Jawa Tengah. Prosiding Seminar Nasional Pendidikan Biologi dan Saintek, UMS Solo 21 Mei 2016. p.1006-1011.

Susanto HM, Rozi ZF, Harmoko. 2017. Inventarisasi Mikroalga di Sungai Kelingi Kecamatan Lubuklinggau Timur I Kota Lubuklinggau. [Internet]. Available from: http:// repository. mipastkipllg. com/.

Vuuren SJV, Jonathan T, Carin VG, Annelise G. 2006. Easy Identification of The Most Common Freshwater Algae. South African: North-West University Noorowes-Universitiet.

Wehr JD, Sheath RG. 2003. Freshwater Algae Of Noert America. America: Academic Press.

Winahyu DA, Yulistia A, Elly L, Rustiati, Jani M, Andi S. 2013. Studi Pendahuluan Mengenai Keanekaragaman Mikroalga di Pusat Konservasi Gajah, Taman Nasional Way Kambas. Prosiding Semirata FMIPA Universitas Lampung, p.93-98.

Winarno K, Astirin OP, Setyawan AD. 2000. Pemantauan kualitas perairan rawa Jabung berdasarkan keanekaragaman dan kekayaan komunitas bentos. BioSMART: Journal of Biological Science. 2(1):40-46.

Zulkifli H, Husnah, Ridho MR, Juanda S. 2009. Status kualitas sungai musi bagian hilir ditinjau dari komunitas fitoplankton. Journal of Biological Researches. 15(1):5-9. 